\title{
Analysis of the Commonly-seen Mistakes in Translation
}

\author{
Linyan $\mathrm{Fu}$
}

\author{
Jiangxi Science \& Technology Normal University, Jiangxi Nanchang 330038
}

\author{
Keywords: Contract text; Understanding; Case analysis; Errors
}

\begin{abstract}
Under the global economic integration trend, the economic and trade exchanges between China and other countries are increasingly frequent. As the legal means and basis to safeguard the rights and interests of both contracting parties, the contract plays an important role in social economic activities. This trend also makes the demand of contract translation increases. In English contract translation practice, the customer requirements for the quality of contract text translation is often reflected in two aspects: accurate and smooth. Accurate and smooth refer to two translation processes: understanding and expression. Therefore, this paper expounds the language characteristics of English contract and points out contract belongs to a kind of legal documents with rigorous law text language characteristics. Begin with the analysis of cases, this paper classifies and analyzes the common mistakes which respectively appear in the processes of understanding and expression, puts forward some coping strategies, and points out that contract text translation should reflect the internal spirit and the stylistic characteristics.
\end{abstract}

\section{Introduction}

With China's accession to WTO and the further deepening of reform and opening up, the economic exchanges between China and other countries are more close. Fair legal contract signing is the premise and guarantee to clear rights and obligations of both parties, safeguard the interests of all parties and conduct business smoothly. International economic activities become frequent and the demand of contract translation increases. This paper only discusses the problems involved in English contract translation.

In contract text translation, the translator should not only have good understanding and excellent bilingual translation skills, but also needs to fully understand the professional knowledge and legal knowledge involved in the corresponding projects in the contract and to fully realize the normalization and legal effect of contract as the legal document, which are practically and vitally related to the economic interests of both contracting parties. Therefore, how to improve the quality of contract text translation has become a realistic subject.

\section{Language Features of English Contract Texts}

Legal document contract is the document to appoint rights and responsibilities and obligations of the contracting parties with legal effect. The language of contract is different from every-day language, writing words are accurate and rigorous, sentences are complicated and language is formal and specified, which reflects accuracy and rigor of logic, professional and the standardization of expression, as well as clarity and organization of thinking. From the aspects of vocabulary to syntax, English contract text manifests the rigorous legal text linguistic characteristics.

In the first place, English contract often uses a lot of technical terms and legal jargons, which have strong professional. In English contract text, the following situations often appear: (1) Ordinary words have professional industry significance; (2) Frequently use ancient words (including Latin and French vocabulary); (3) Large number of technical terms and legal jargons; (4) Synonyms, homoionym and related words are used parallelly, etc.

Second, English contract uses a large number of long distance, numerous modifiers and complexed sentences, since the authorization of English contract is very rigorous. There are large number of additional components and insert elements to show the limitation which are used as 
explanation, introduction, limitation and supplement.

Third, English contract text has a rigorous structure and formal language. Translators can make full use of parallel text and compare the formats of the English contract texts of China and foreign countries. From the structure of the whole text, sentence structure and language, understand the language difference between the contract texts of China and foreign countries and understand the characteristics of English contract.

\section{Analysis of misunderstanding of words meanings}

In English contract translation process, the misunderstanding of vocabulary in the original text is often because of not being familiar with related legal background meaning of vocabulary, especially the law meaning of the common vocabulary, not understanding the meaning of related professional terms and being lack of logic judgment, etc.

In legal English, some words have common forms, but the meanings belong to legal terms. These words tend to be the polysemy vocabulary in ordinary English, which needs the help of understanding the original meaning through certain context to determine its meaning.

Example 1:

Original text: NEITHER PARTY WILL BE LIABLE FOR ANY INDIRECT, SPECIAL, INCIDENTAL CONSEQUENTIAL, EXEMPLARY OR PUNITIVE DAMAGES ARISING OUT OF THIS AGREEMENT $\cdots \cdots . .$.

Original translation: Either party shall not be responsible for any indirect, special, accidental, derivative, discipline, or punitive damages caused by this agreement.

Revision translation: Either party shall not be responsible for any compensation for damages of the indirect, special, accidental, derivative, discipline, or punitive damages caused by this agreement.

Analysis: the translator in the original translation confuses "damages" with "damage". "Damages" appears to be the plural form of "damage", but we should note that when "damage" is a noun with the meanings of "loss, destroy", it is an uncountable noun. Therefore, it is wrong to consider "damages" as the plural form of "damage". Due to the lack of enough legal expertise, the original translator automatically translated according to the usual meaning of the word when facing a seemingly common word. This kind of error is very dangerous, which may not be found even if the translator returns to exam the whole translation.

\section{Case Analysis of Misunderstanding of Sentence Structure}

Not all the long sentences in English contract are necessarily complex compound sentence. Some simple sentences will be very long. Too many modifications, such as participles and phases make it difficult to understand the whole sentence. To understand the sentences, especially the complex long sentences becomes a common "obstacle" in the understanding of the original text of English contract translation.

Example 2:

Original text: XX's waiver of any breach or failure to enforce any of the terms and conditions of this License Agreement at any time shall not in any way affect, limit or waive XX's right thereafter to enforce and compel strict compliance with every term and condition hereof.

Original translation: At any time, XX gives up any default or any terms and conditions which cannot perform this license agreement, XX shall not be in any way affected or limited or waive each of the following terms and conditions which are implemented and enforced, as well as strictly abide by.

Revision translation: At any time, $\mathrm{XX}$ gives up any default or any terms and conditions which cannot perform this license agreement by YY, and YY shall not be in any way affected or limited or waive each of the following terms and conditions which are implemented and enforced, as well as strictly abide by.

Analysis: In this case, the original translator did not understand the original meaning the text 
conveys and did not clear the rights and obligations relationship between both parties, which leads to mechanical translation, which cannot be understood. This sentence is about "XX"'s rights, but the translation seems to become "XX"'s obligation. In this sentence, "waiver of any breach" literally is "to give up any default", but is actually to "give up default (responsibility) of the other party of the contract". "Failure to enforce any of the terms and the conditions" is not "cannot perform any terms and conditions of this agreement" (the expression is like that "is unable to perform its obligations"), but "not required (the other party) to strictly implement the terms and conditions of this agreement". Similarly, the following "enforce and compel strict compliance with" does not refer to "XX" oneself "implements and enforces strict adherence to", but "require (the other party) to strictly abide". It is also needed to point out that although the original name of the other party does not appear in the contract, for the sake of clarity of expression, according to the needs of context adaptation, the omitted information shall be added.

\section{Case Analysis of the Mistakes Caused by being Lack of Professional Knowledge}

In the understanding of English contract text, translators must have a legal background knowledge. The understanding of western legal culture, especially of the legal history knowledge, helps to understand the communication intentions of the original contract text quickly and accurately, which helps translators better translate English contract.

\section{Example 3:}

Original text: Except as specifically provided for in this License Agreement, the rights and remedies of the parties set forth herein shall be cumulative and in addition to any rights and remedies available to them at law and/or in equity.

Original translation: Except as otherwise specified in this agreement, the rights and remedies of the two parties under this agreement shall be cumulative and shall be the remedies of any right and relief under the law and/or the principle of fair.

Revision translation: Except as otherwise specified in this agreement, the rights and remedies of the two parties under this agreement shall be cumulative and shall be the remedies of any right and relief under Common Law and Equity.

Analysis: Legal professionals commonly understand the remedy of Common law is only damages, including money damages and return of property, in which money damages is given priority to; while the remedies of Equity are more. In addition to damages, there are perform according to the agreement, ban, etc. According to background knowledge of the law, it is known that "at law and/or in equity" here refers to respectively Common law and Equity. Because the translator did not understand basic knowledge of Anglo-American law, and translated law and equity into the law and the principle of fair for the common sense, which deviated from the original intention and led to translation mistakes.

\section{Conclusion}

As a kind of legal documents, contract text translation standards comply with the principles of the translation of legal texts. Accuracy is the soul and life of legal language. So-called accuracy is to request the legal document to have a clear and specific expression. The translation text shall try to get rid of the influence of Chinese thinking habits and pay much attention to the differences in expressions of the two kinds of languages. It shall be absolutely avoided to use wrong words which is result in losing accuracy and causing different legal consequences. Contract text translation mainly shall be accurate, rigorous, standardized and smooth which requires translators to use appropriate words, and to follow the characteristics of legal language and to reflect the stylistic characteristics of contract as far as possible, as well as to arrange the translation in Chinese grammar which is clear and easy to understand.

In short, to better translate the contract texts, translators should not only have a strong sense of responsibility and enough professional knowledge, but also should have good bilingual skills and solid translation theories. 


\section{References}

[1] Lyne, Raphael. Studies in English translation and imitation of Ovid, 1567-1609.[J]. Embo Journal, 1996, 17(1):61 - 70 .

[2] Walras L. Elements of pure economics, 1874. English translation by William Jaffé, published by Allen and Unwin[J]. 1954.

[3] K.F Feng, New Theory of Ideological and Political Education Principles in Institutions[J]. Journal of Southwest China Normal University, 2005.

[4] Z Wang, Yumei M A. Thematic Analysis of "Song of the Lime" and Its English Translation from the Perspective of Functional Linguistics[J]. Journal of Educational Institute of Jilin Province, 2014, 14(8):783-790.

[5] Jonathon R. B. Halbesleben, Evangelia Demerouti. The construct validity of an alternative measure of burnout: Investigating the English translation of the Oldenburg Burnout Inventory[J]. Work \& Stress, 2005, 19(3):208-220.

[6] Quetelet L A J. A treatise on man and the development of his faculties (A facsimile reproduction of the English translation of 1842 with an introduction by Solomon Diamond).[J]. 1969.

[7] Y Wang, Chinese-English Translation of Public Signs:Miscellaneous Errors and Relevant Translation Theories[J]. Journal of Beijing International Studies University, 2007, 283(24):5058-5061.

[8] Hefa L. On Functional Features and Chinese-English Translation of the Expressions on Public Signs[J]. Terminology Standardization \& Information Technology, 2005.

[9] William Martin, Klaus Kowallik. Annotated English translation of Mereschkowsky's 1905 paper 'Über Natur und Ursprung der Chromatophoren imPflanzenreiche' [J]. European Journal of Phycology, 1999, 34(3):287-295.

[10]Cerf W. The Difference Between Fichte's and Schelling's System of Philosophy: An English Translation of G. W. F. Hegel' s Differenz des Fichte' Schen Und Schelling' Schen Systems der Philosophie[J]. Philosophy, 1977.

[11]C Li, English Translation of Signs and Words of Caution in Public Places[J]. Chinese Translators Journal, 2003.

[12] Sexton K A, Dugas M J. The Cognitive Avoidance Questionnaire: validation of the English translation.[J]. Journal of Anxiety Disorders, 2008, 22(3):355. 